\title{
Correction to: Combined hepatocellular-cholangiocarcinoma: can we use contrast-enhanced ultrasound Liver Imaging Reporting and Data System (LI-RADS) to predict the patient's survival?
}

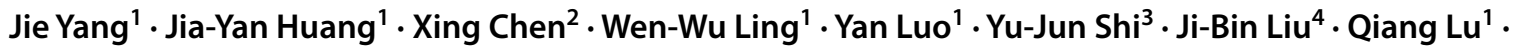 \\ Andrej Lyshchik ${ }^{4}$
}

Published online: 14 October 2021

(c) European Society of Radiology 2021

\section{Correction to: European Radiology (2021) 31:6397-6405}

https://doi.org/10.1007/s00330-020-07656-1

The original version of this article, published on 25 January 2021, unfortunately contained a mistake. The definitions of the colored curves in Figure 4 were interchanged; the figure should have appeared as shown below. The original article has been corrected.

Publisher's note Springer Nature remains neutral with regard to jurisdictional claims in published maps and institutional affiliations.

The online version of the original article can be found at https:// doi.org/10.1007/s00330-020-07656-1

Qiang Lu

luqiang@scu.edu.cn

1 Department of Ultrasound, West China Hospital of Sichuan University, Sichuan Province, No. 37 Guo Xue Xiang,

Chengdu, China

2 Department of General Surgery, West China Hospital of Sichuan University, Sichuan Province, No. 37 Guo Xue Xiang, Chengdu, China

3 Department of Pathology, West China Hospital of Sichuan University, Sichuan Province, No. 37 Guo Xue Xiang, Chengdu, China

4 Department of Radiology, Thomas Jefferson University Hospital, Philadelphia, PA, USA 
Fig. 4 Kaplan-Meier survival curve for disease-free survival time after curative resection of combined hepatocellularcholangiocarcinoma (category LR-5 vs LR-M or TIV patients)

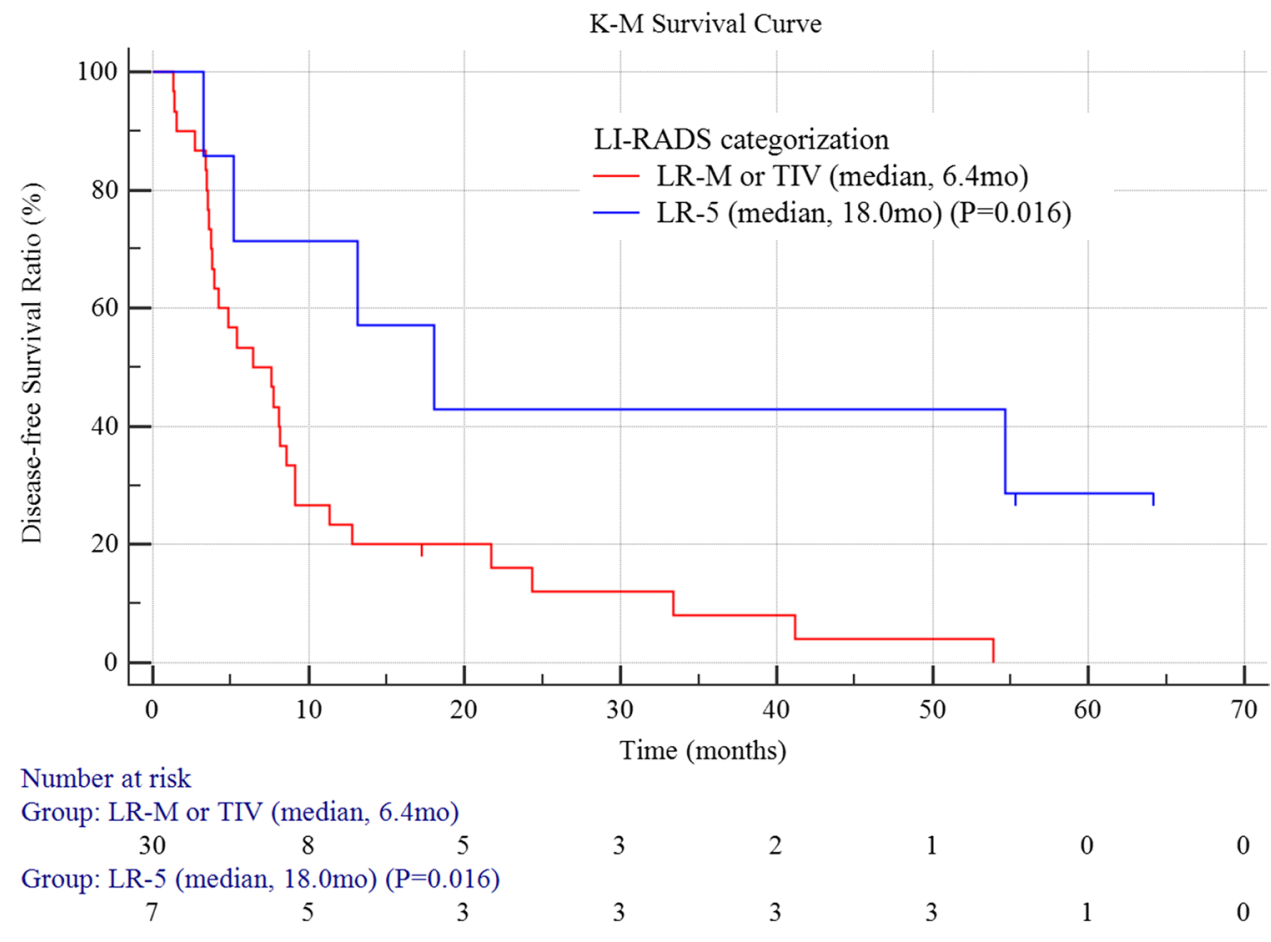

